\title{
Comparison of Maternal Anemia and Their Infant Apgar Scores in Conventional Vaginal Delivery with Physiological Delivery
}

\author{
Khodayar Oshvandi ${ }^{1}$, Seyedeh Zahra Masoumi ${ }^{2}$, Farideh Kazemi ${ }^{3}$, Arezoo Shayan ${ }^{* 3}$, \\ Seyed Saleh Oliaei ${ }^{4}$, Afshin Mohammadi ${ }^{4}$
}

1. Professor, Hamadan University of Medical Sciences, Hamadan, Iran

2. Associated professor, School of Nursing and Midwifery, Hamadan University of Medical Sciences, Hamadan, Iran

3. Lecturer, Hamadan University of Medical Sciences, Hamadan, Iran

4. Research Center of Iranian Blood Transfusion Organization, Hamadan Blood Center, Hamadan, Iran

\begin{tabular}{|c|c|}
\hline Article Info & ABSTRACT \\
\hline Received: 2020/04/05; & $\begin{array}{l}\text { Introduction: The aim of this study was to compare some of the maternal blood } \\
\text { parameters and Apgar score of their infants in conventional vaginal delivery with } \\
\text { physiological delivery. }\end{array}$ \\
\hline Published Online: 2020/11/2 & $\begin{array}{l}\text { Methods: This semi-experimental study was performed in } 2018 \text { with the participation of } \\
400 \text { pregnant women candidates for physiological childbirth and } 400 \text { pregnant women }\end{array}$ \\
\hline doi 10.30699 /ajnmc.28.4.9 & $\begin{array}{l}\text { candidates for conventional vaginal delivery, using the available sampling method. Mothers } \\
\text { in the physiological delivery group were those who did not receive any major labor } \\
\text { intervention, and during the labor, training was given on how to breathe, pelvic rotation, } \\
\text { delivery ball, hot shower, and massage. In the common vaginal delivery group, the mother } \\
\text { went through the usual steps as soon as she was hospitalized. All mothers' intravenous blood } \\
\text { samples were examined in two groups to measure the amount of hemoglobin and hematocrit }\end{array}$ \\
\hline $\begin{array}{l}\text { Use your device to scan } \\
\text { and read the article online }\end{array}$ & $\begin{array}{l}\text { at the time of hospitalization and } 6 \text { hours after delivery and the Apgar score of the first and } \\
\text { fifth minutes of infancy in both groups. Data analysis was performed using Stata- } 13 \text { software } \\
\text { and the significance level was considered to be } 0.05 \text {. }\end{array}$ \\
\hline
\end{tabular}

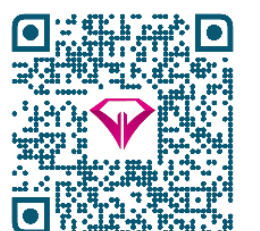

Results: The mean age of Hemoglobin and Hematocrit in the conventional vaginal delivery group was $27.37(5.75)$ years and in the physiological delivery group was $27.70(5.73)$ years. The results showed that at the time of hospitalization, the mean hemoglobin in the physiological delivery group was significantly higher than the conventional vaginal delivery $11.64(1.20)$ and $11.93(1.20)$, respectively $(P<0.001)$. The results showed that at the time of hospitalization, the mean hematocrit in the physiological delivery group was significantly higher than conventional vaginal delivery 36.53 (3.33) and 35.50 (3.33), respectively $(P<0.001)$. Comparison of the Apgar scores of the newborns in two groups in the $1^{\text {st }}$ and $5^{\text {th }}$ minutes also showed that the Apgar score in the physiological delivery group was higher than the conventional vaginal delivery $(P<0.05)$.

Conclusion: The results showed that at 6 hours postpartum, the mean of hemoglobin and hematocrit in the physiological delivery group was significantly higher than conventional vaginal delivery $(P<0.001)$. Comparison of neonatal Apgar scores of the two groups in minute 1 and minute 5 also showed that the amount of Apgar score in physiological delivery group was higher than conventional vaginal delivery $(P<0.05)$.

Keywords: Childbirth, Mothers, Anemia, Apgar, Babies

Corresponding Information:

Arezoo Shayan, Lecturer, Hamadan University of Medical Sciences, Hamadan, Iran Email: arezoo.shayan2012@yahoo.com

Copyright $(C)$ 2020, This is an original open-access article distributed under the terms of the Creative Commons Attribution-noncommercial 4.0 International License which permits copy and redistribution of the material just in noncommercial usages with proper citation.

How to Cite This Article:

Oshvandi K, Masoumi Z, Kazemi F, Shayan A. Comparison of Maternal Anemia and Their Infant Apgar Scores in Conventional Vaginal Delivery with Physiological Delivery. Avicenna J Nurs Midwifery Care. 2020; 28 (4):9-19 
مقايسة برخى يارامترهاى خونى مادران و نمرات آيعار نوزادان آنها در روش زايمان وازينال مرسوم با زايمان فيزيولوزيك

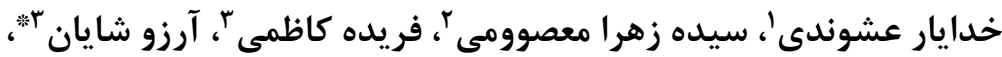

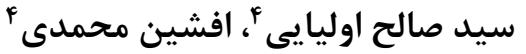

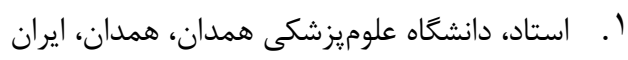

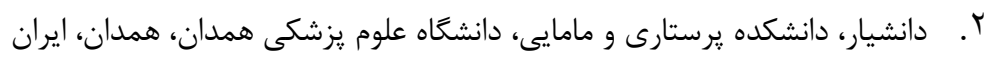

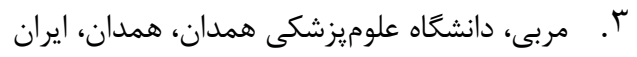

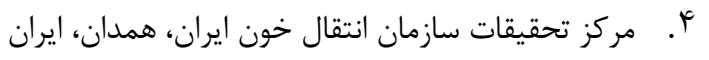

\begin{tabular}{|c|c|}
\hline جكيده & اطلاعات مقاله \\
\hline 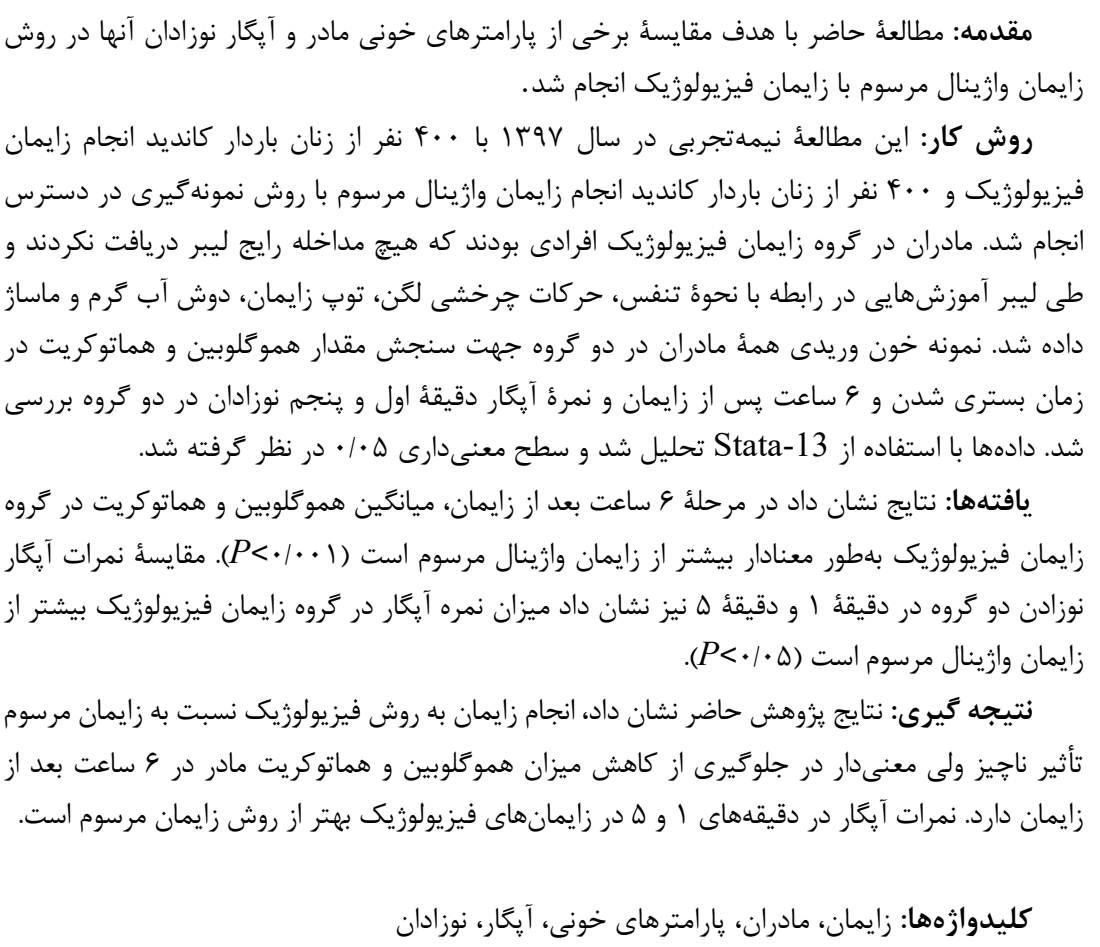 & 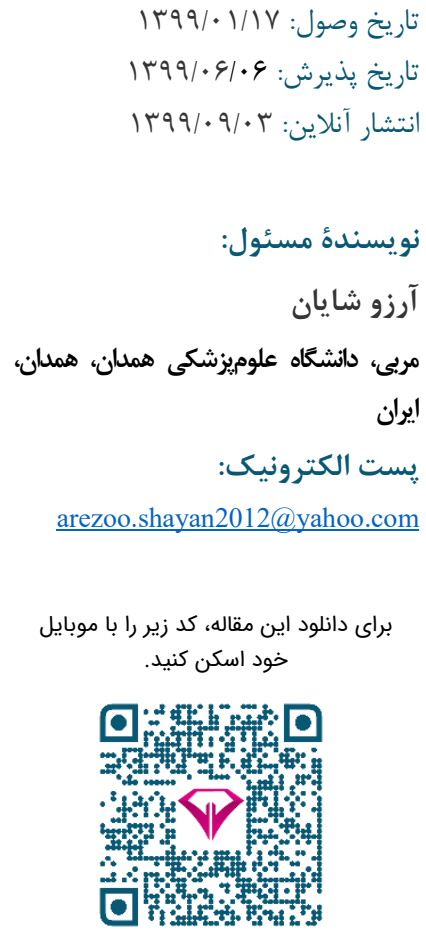 \\
\hline
\end{tabular}

مقدمه - - مقد

كه از بين آنها حدود •^أهزار نفر مىميرند [N]. خونريزى

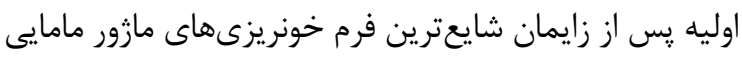

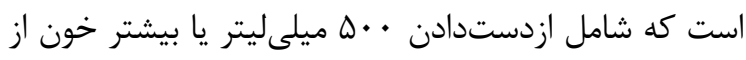

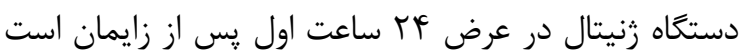

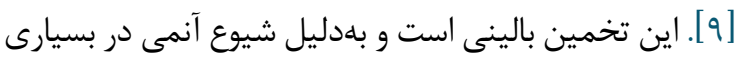

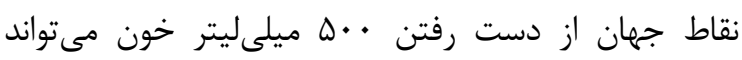

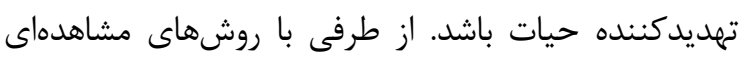

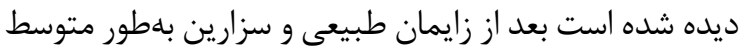

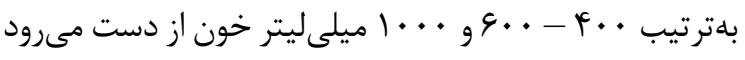

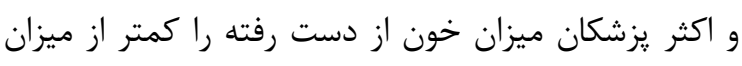

باردارى و زايمان تجربؤ بزرگى در زندگى يك زن محسوب

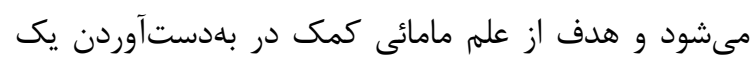

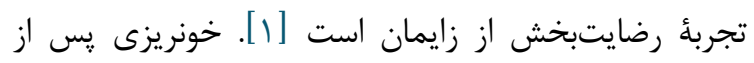

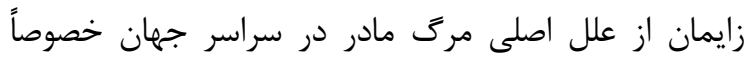
كشورهاى در حال توسعه بوده و مسئول سار دار درصد موارد

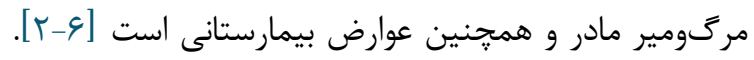

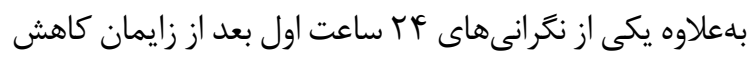

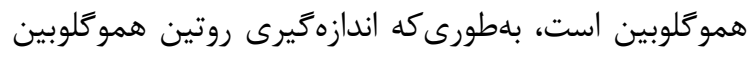

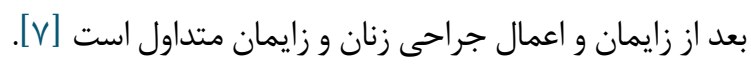

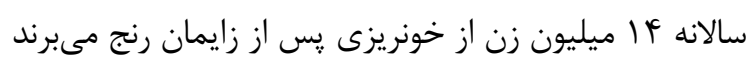


و يافتههاى متفاوتى ززارش شده، ولى يافتن روش درمانى

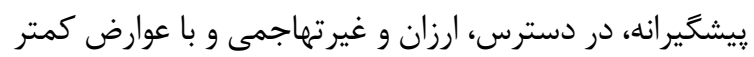

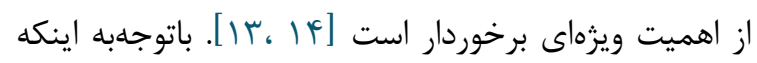

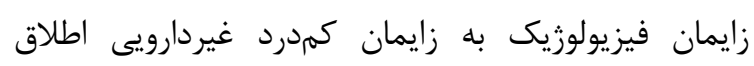
مىشود و حداقل مداخلات زايمانى ازجمله استفاده ازئي

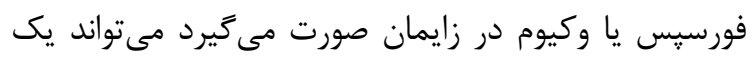

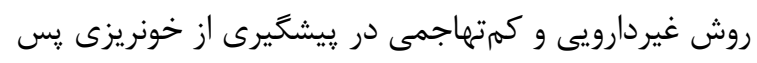

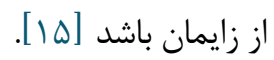
تاكنون در مطالعات انجامشده، بيان شده است كه زايمان

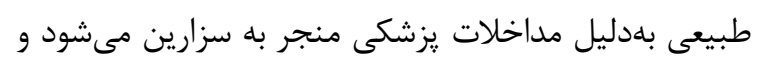

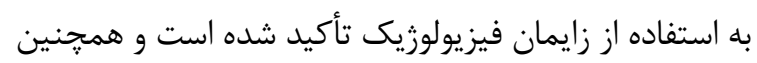

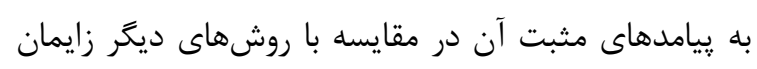

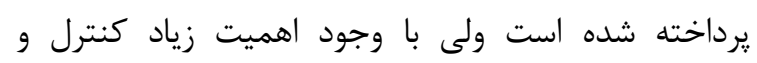

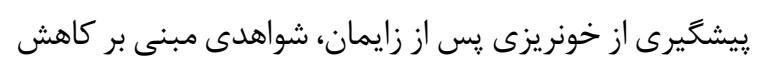

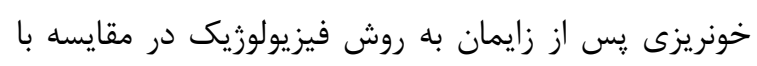

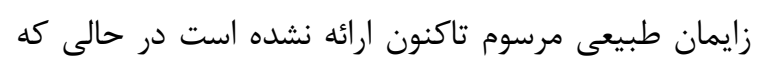

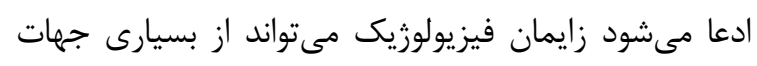

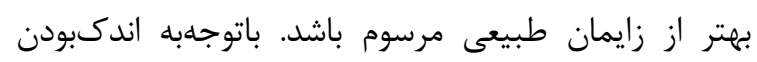

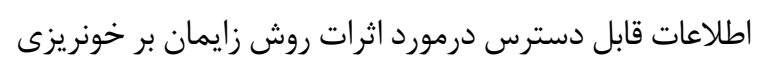

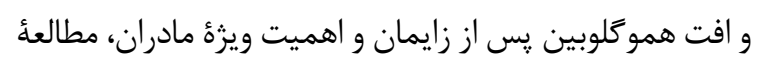

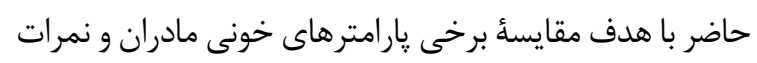

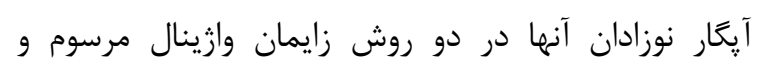

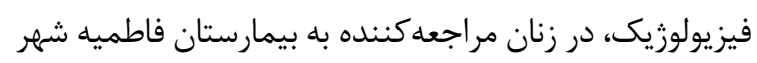

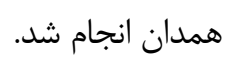

\section{روشبررسى}

مطالعئ حاضر بلهورت نيمهتجربى با شركت زنان باردارى

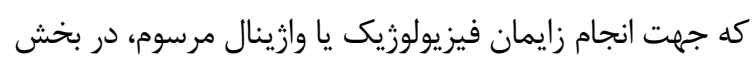

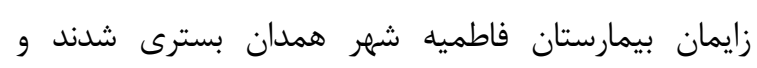

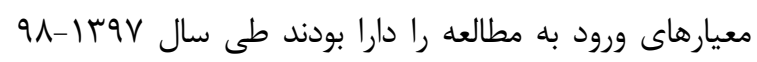

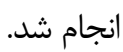

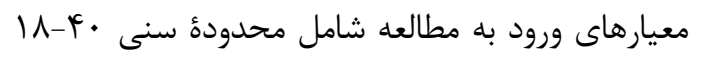

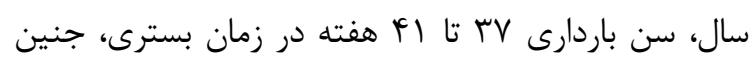

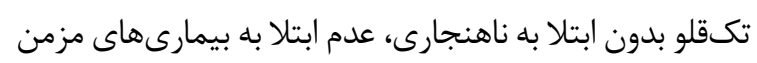
مانند بيمارىهاى قلبىريوى، كليوى، ديابت، اختلالات خونى باني

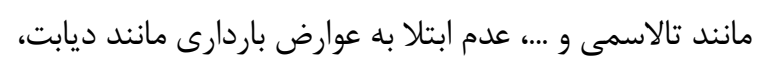

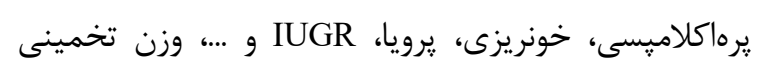

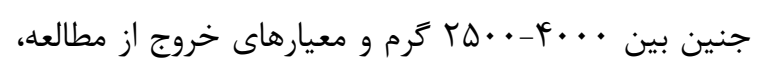

واقعى برآورد مى كنند [ع]. در نيمى از زنانى كه با روش

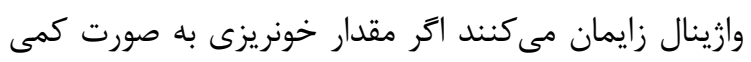

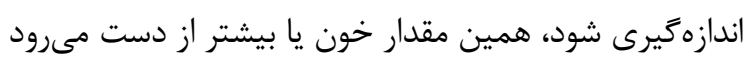

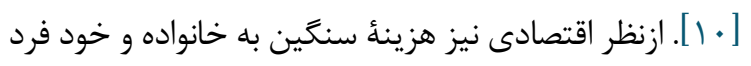

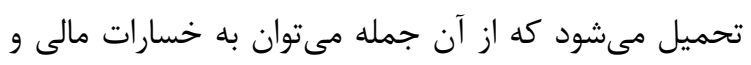
ناتوانائىهاى جسمى ناشى از بسترى در در بيمارستان، انت انتقال

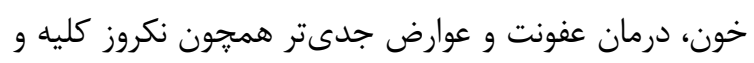

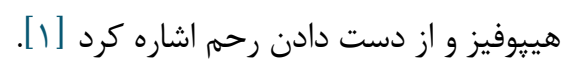

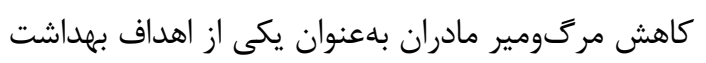

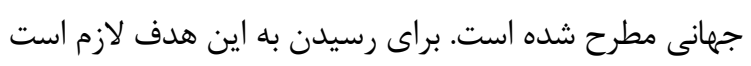

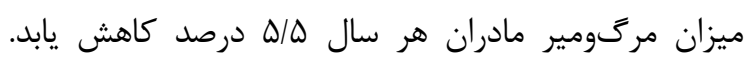

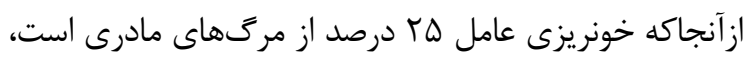

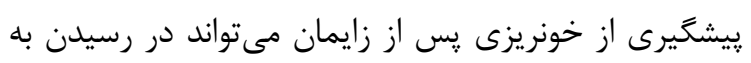

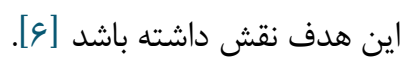

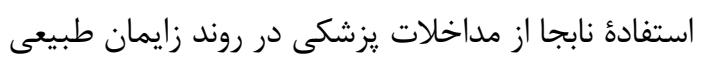

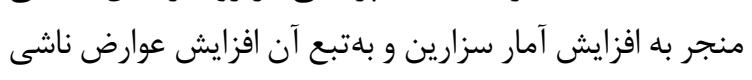

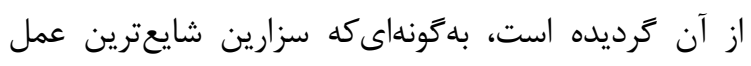

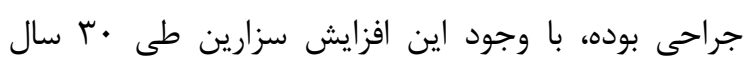

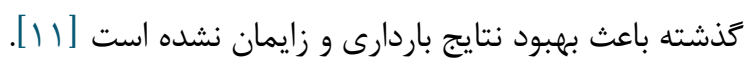
به همين منظور براى دستيابى به زايمانى ايمن، ديدكاه زايمان

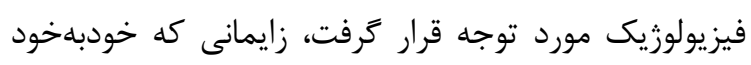

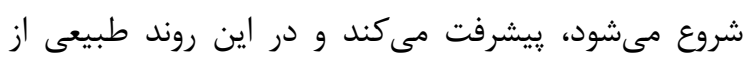

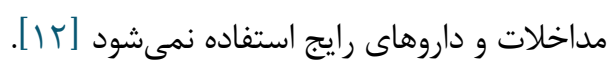

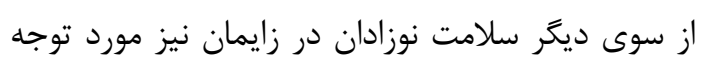

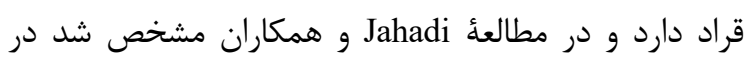
زايمان فيزولوزيك درمقايسهبا زايمان طبيعى، آيخار دقيقهُ اول

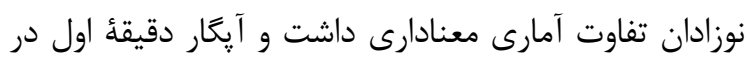
كروه زايمان فيزيولوزيك بهتر بود.

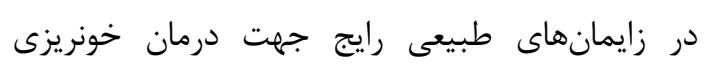

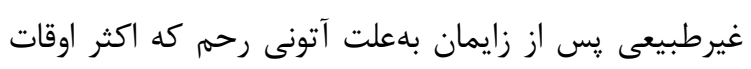

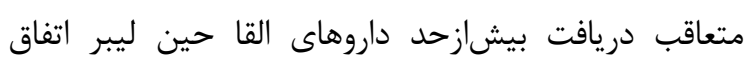

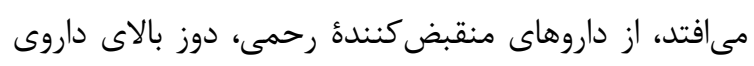

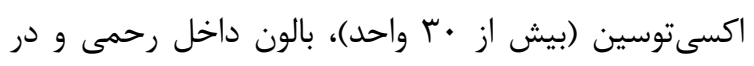

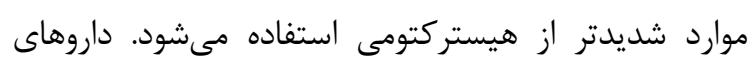

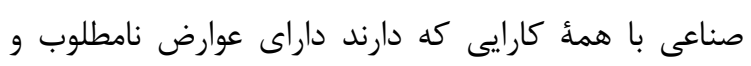

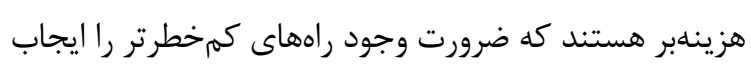
مى كند. درزمينهُ درمانهاى طبى و غيرطبى دربئ درباره خونريزى

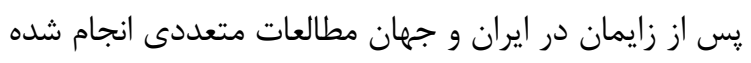


بهمنظور ثبت اطلاعات مرتبط با اهداف يروهش استفاده شد.

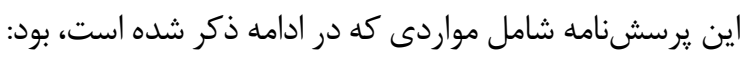

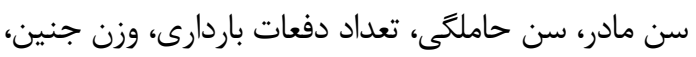

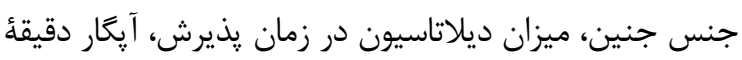

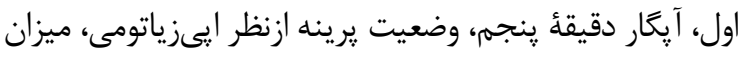

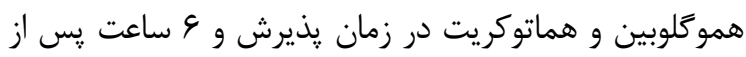

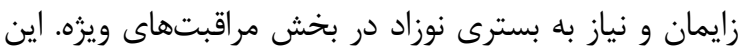

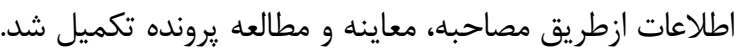

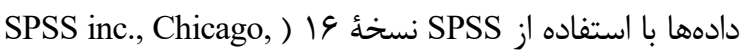
تحليل شد. براى بررسى توزيع متغيرهاى كمى از (IIl., USA

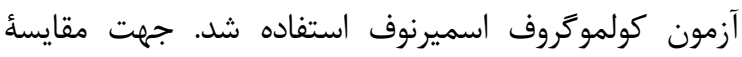

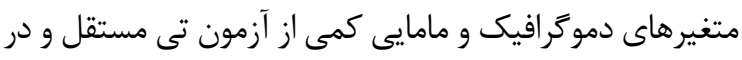

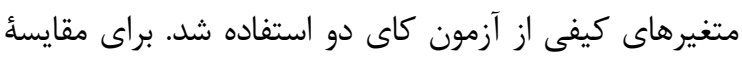

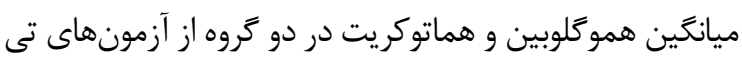

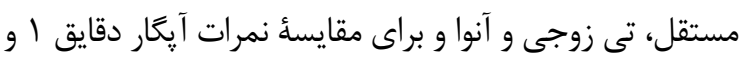

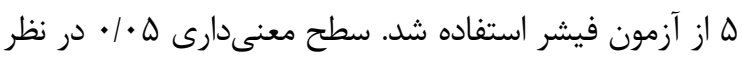
كرفته شد.

\section{يافته ها}

توزيع همأ متغيرهاى كمى باتوجلبه نتايج آزمون كولموكروف

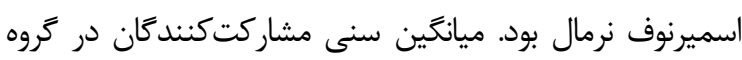

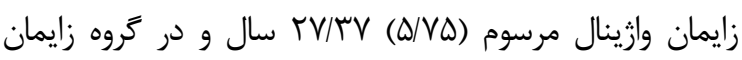

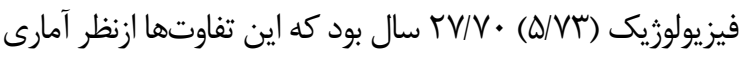

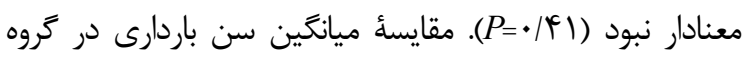

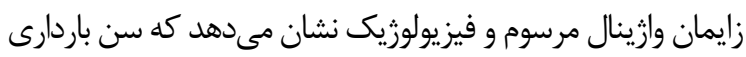
در كروه زايمان فيزيولوزيك بيشتر از گروه زايمان وازينال مرسوم

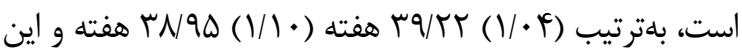

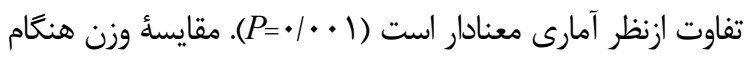

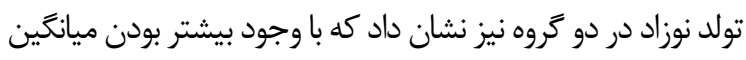

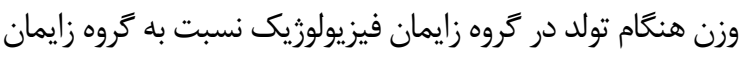

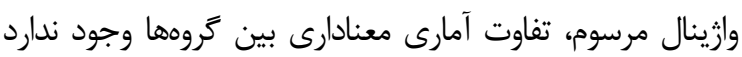

حدود يكسوم از شركت كنندًان در يزوهش حاملكى اول

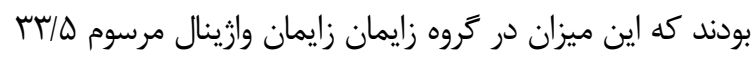

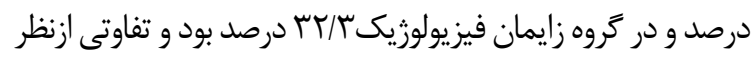

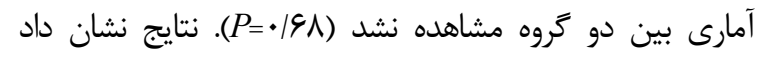

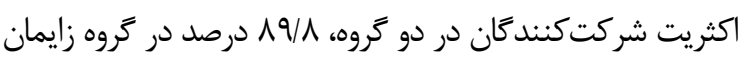

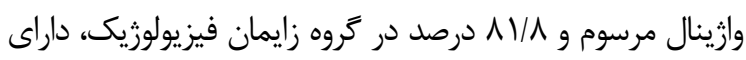
سابقه سقط نبودند و اين تفاوت ازنظر آمارى معنادار بود درد
بروز هرگونه عارضه در حين ليبر و زايمان و نياز به انجام سزارين يارگى وازن و سرويكس يا رحم بود.

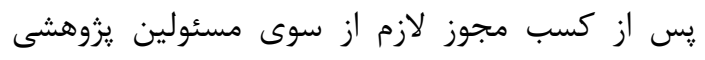

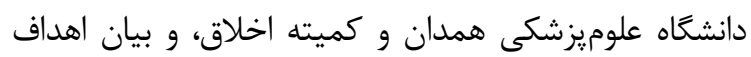

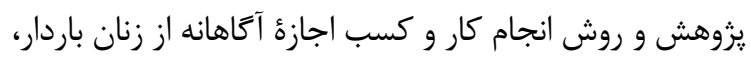

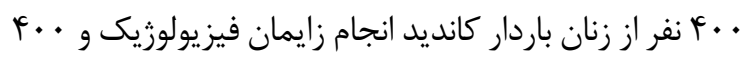

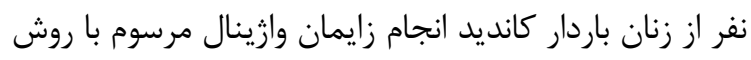

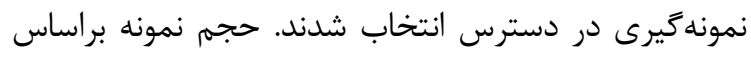

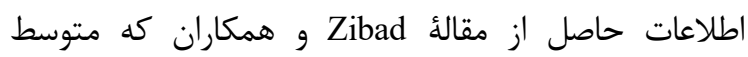

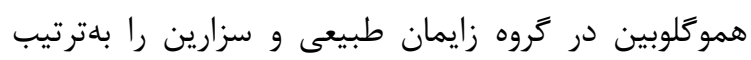

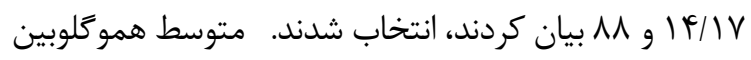

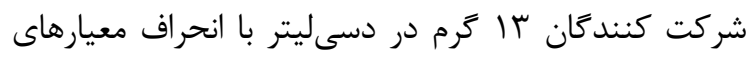

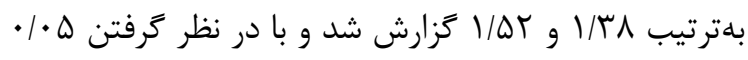

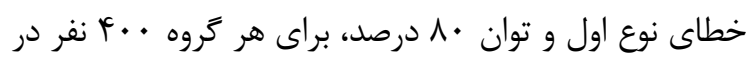

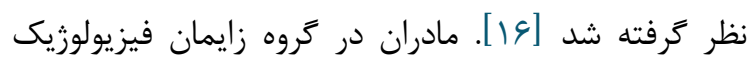
افرادى بودند كه هيج مداخلة رايج ليبر شامل انفوزيون مايعات

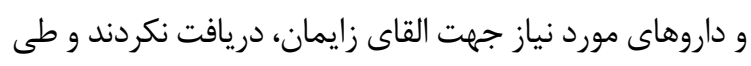

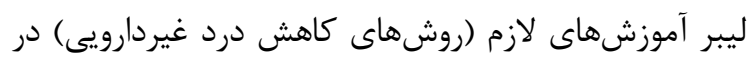

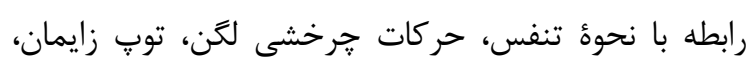

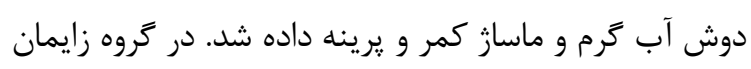

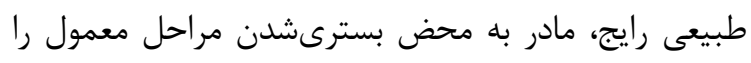

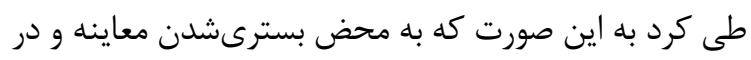

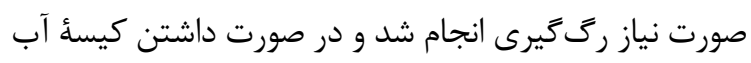

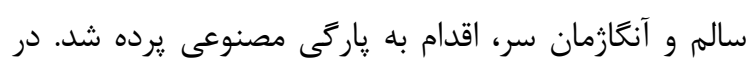
صورت داشتن دستور يزشكى مبنى بر تحريك يا تشديد ليبر

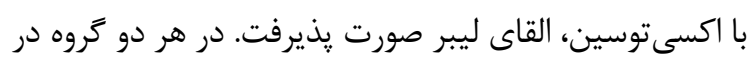

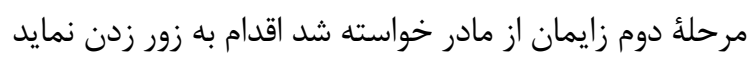

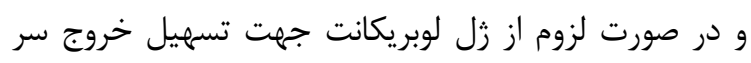

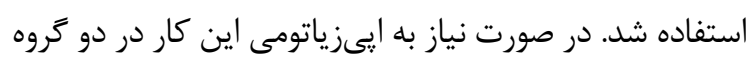

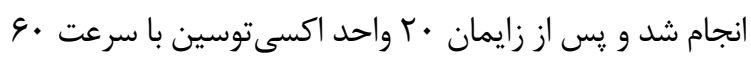

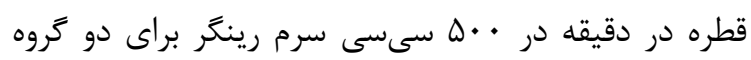

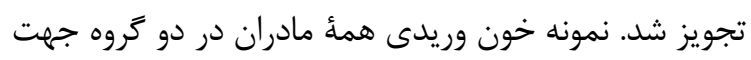

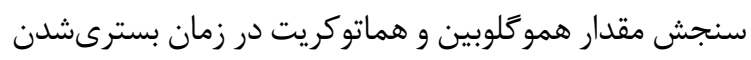

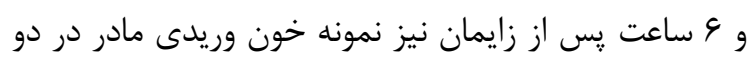

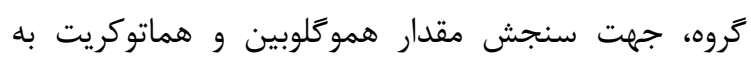

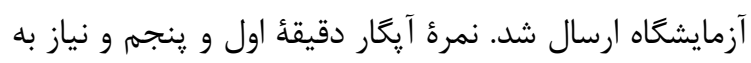

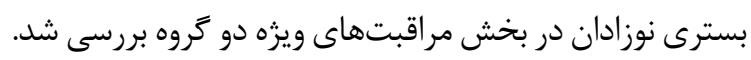

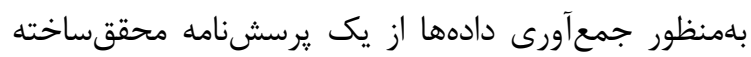




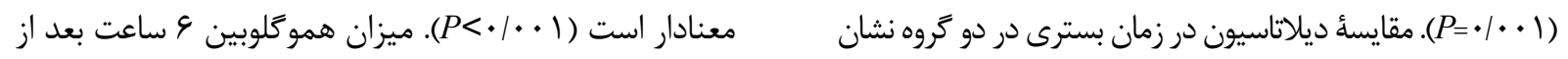

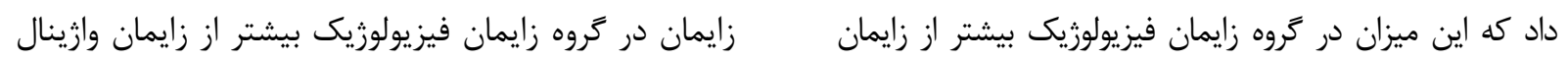

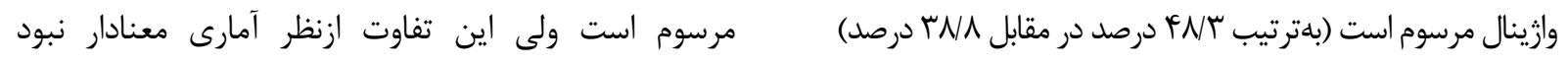

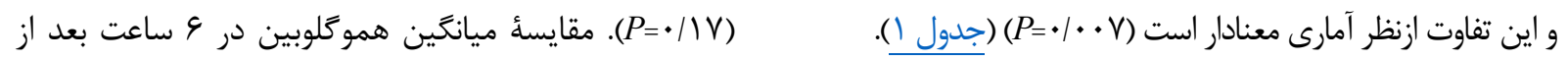

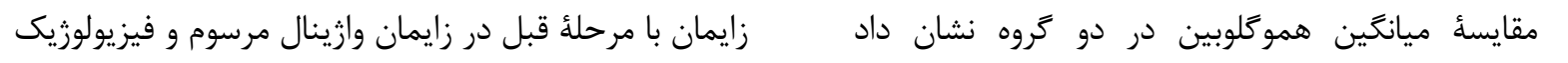

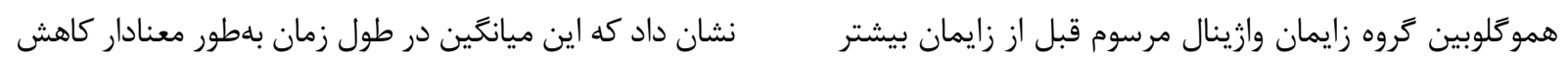

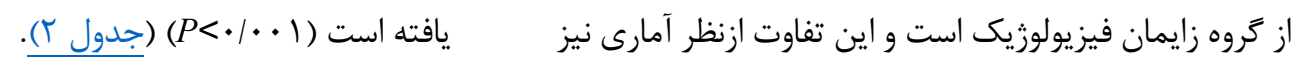

جدول ا. مقايسهُ متغيرهاى دموكرافيك و مامايى طبقهبندى شده مشار كتكنندكان

\begin{tabular}{|c|c|c|c|c|}
\hline$P$ & آزماره & $\begin{array}{c}\text { زايمان فيزيولوزيك } \\
\text { Mean (SD) } \\
\text { N=r.. }\end{array}$ & $\begin{array}{c}\text { زايمان طبيعى } \\
\text { Mean (SD) } \\
\mathrm{N}=\uparrow \ldots\end{array}$ & متغير \\
\hline \multirow{5}{*}{$\cdot 19 \Lambda$} & \multirow{5}{*}{$\cdot / V F$} & & & تعداد باردارى \\
\hline & & ITq (Tr/T) & $\mid K F(T r / Q)$ & 1 \\
\hline & & I $\Delta \Gamma(\Gamma / / \Gamma)$ & $109(\Upsilon 9 / \wedge)$ & r \\
\hline & & $111(r 9 / \Delta)$ & 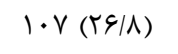 & $\geq r$ \\
\hline & & & & تعداد زايمان \\
\hline \multirow{3}{*}{ - ATt } & \multirow{3}{*}{ • } & $1 \% q(\Gamma r / T)$ & $\operatorname{IrF}(\Psi \Psi / \Delta)$ & · \\
\hline & & $\mid f \&(\Psi \varepsilon / D)$ & $1 F q(T V / T)$ & 1 \\
\hline & & $1 T \Delta(T / T)$ & $11 V(r q / r)$ & $\geq r$ \\
\hline \multirow{4}{*}{$\cdot 1 \cdot \cdot 1$} & \multirow{4}{*}{$1 \cdot / 4 V$} & & & سابقهُ سقط \\
\hline & & $V \Gamma(\mid \Lambda / r)$ & $|f|(1 \cdot / r)$ & 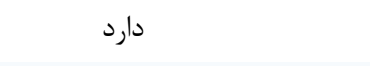 \\
\hline & & 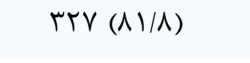 & 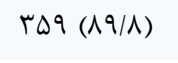 & 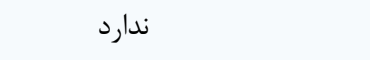 \\
\hline & & & & ديلاتاسيون سرويكس در زمان \\
\hline \multirow{2}{*}{$\cdot / \cdot v$} & \multirow{2}{*}{ V/TY } & $r \cdot V(\Delta I / \Lambda)$ & $T F \Delta(\varepsilon / / T)$ & $r>$ \\
\hline & & $19 \pi(\mathcal{F} / /)$ & $1 \Delta \Delta(\Gamma \Lambda / \Lambda)$ & $k \leq$ \\
\hline
\end{tabular}

\begin{tabular}{|c|c|c|c|c|}
\hline$P^{*}$ & $\mathrm{~T}$ & $\begin{array}{c}\text { زايمان فيزيولوزيك } \\
\text { Mean (SD) } \\
N=\text { f. }^{\circ}\end{array}$ & $\begin{array}{c}\text { زايمان طبيعى } \\
\text { Mean (SD) } \\
\mathrm{N}=\varphi_{\text {.. }}\end{array}$ & هر حلهُ سنجش \\
\hline$<\cdot 1 \cdot \cdot 1$ & $r / q r$ & $\mid r / 49(1 / T \cdot)$ & $I T / V \wedge(I / \cdot F)$ & قبل از زايمان \\
\hline \multirow[t]{3}{*}{.$/ 1 \mathrm{~V}$} & \multirow[t]{3}{*}{$-1 / \pi \omega$} & $11 / \wedge \Delta(1 / r Y)$ & $\| / N r(1 / \Gamma \wedge)$ & \multirow[t]{2}{*}{ ع ساعت بعد از زايمان } \\
\hline & & $\begin{array}{c}\mathrm{T}=\mid r / \uparrow \varphi \\
* * * \cdot \cdots \mid\end{array}$ & $\begin{array}{c}\mathrm{T}=\mid \& / \& \Delta \\
* * \cdot|\cdot| \cdot \mid\end{array}$ & \\
\hline & & & تى زوجى & * آزمون تى مستقل ، \\
\hline
\end{tabular}


در گروه زايمان فيزيولوزيك بهطور معنادار بيشتر از زايمان

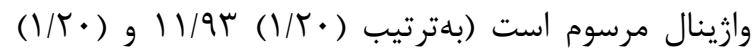

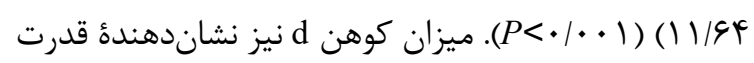

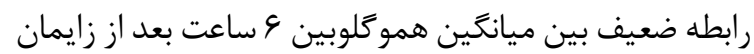

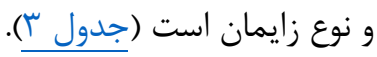

براى كنترل عوامل مداخلهكر احتمالى بر ميزان

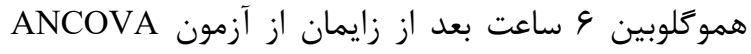

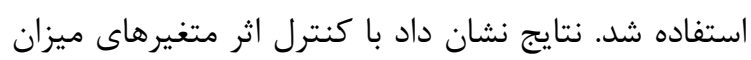
هموَلوبين قبل از زايمان، سن باردارى، سابقه سقط و

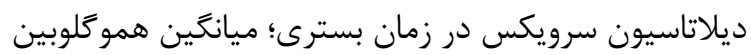

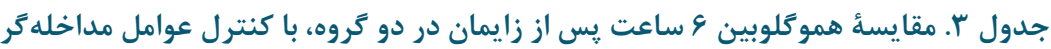

${ }^{* *} P \quad$ F $\quad \quad{ }^{*}$ Cohen's d 95\% CI $\quad$ Adjusted mean (SD)

تروه زايمان طبيعى

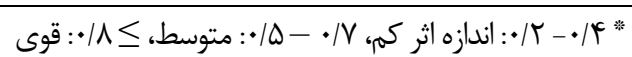

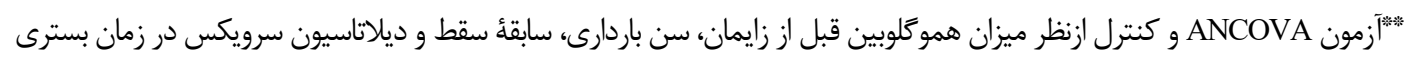

زايمان وازينال مرسوم بود و اين تفاوت نيز ازنظر آمارى (P) معاد

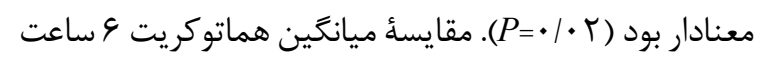

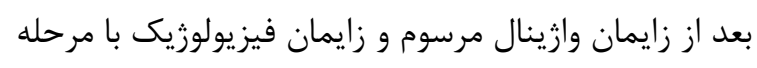

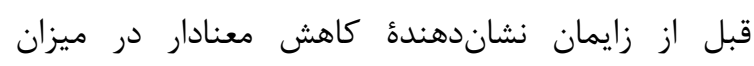

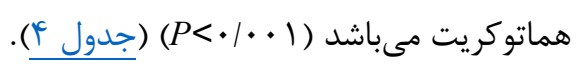

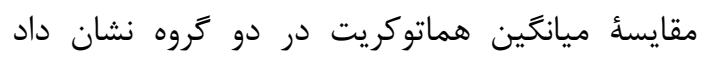

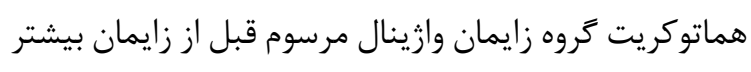

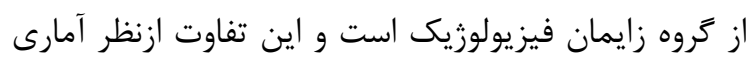

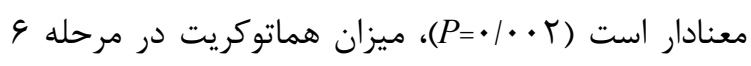

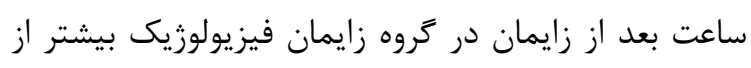

جدول f. مقايسُٔ ميانگين هماتوكريت قبل از زايمان و \& ساعت بعد زايمان بين دو تروه

\begin{tabular}{|c|c|c|c|c|}
\hline$" P$ & $\mathbf{T}$ & $\begin{array}{c}\text { كروه زايمان فيزيولوزيك } \\
\text { Mean (SD) } \\
\text { N=F.. }\end{array}$ & $\begin{array}{c}\text { كروه زايمان طبيعى } \\
\text { Mean (SD) } \\
N=f_{.+.}\end{array}$ & هماتوكر حليت سنجش \\
\hline$\cdot \cdot \cdot r$ & $r / l$. & $r V / \uparrow \&(T / r \cdot)$ & rN/IY (T/Vq) & قبل از زايمان \\
\hline \multirow[t]{2}{*}{$.1 \cdot r$} & \multirow[t]{2}{*}{$-t / T V$} & 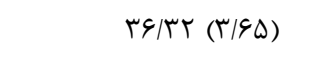 & $r \Delta / V \backslash(\Gamma / q \varphi)$ & \multirow[t]{2}{*}{ ع ساعت بعد از زايمان } \\
\hline & & $\begin{array}{c}\mathrm{T}=\Lambda / 9 \Lambda \\
" P<\cdot|\cdot \cdot|\end{array}$ & $\begin{array}{l}\mathrm{T}=11 / V \mathrm{~T} \\
{ }^{*} P<\cdot \mid . .1\end{array}$ & \\
\hline
\end{tabular}

$$
\text { * * آزمون تى مستقل ، *** آزمون تى زوجى }
$$

در كروه زايمان فيزيولوزيك بهطور معنادار بيشتر از زايمان

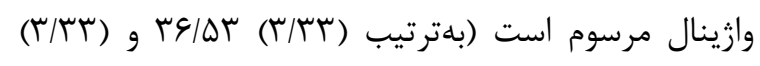

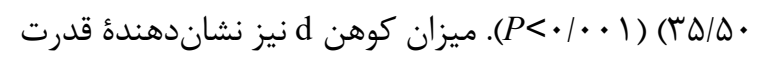

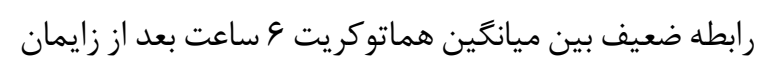

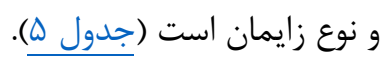

براى كنترل عوامل مداخلهكر احتمالى بر ميزان هماتوكريت 9 ساعت يس از زايمان از آزمون آنكووا استفاده

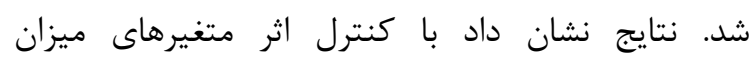

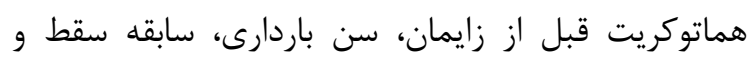

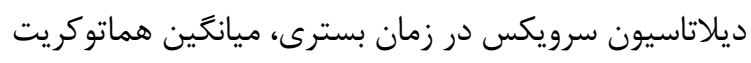

\begin{tabular}{|c|c|c|c|c|}
\hline${ }^{* *} P$ & $\mathrm{~F}$ & ${ }^{*}$ Cohen's d 95\% CI & Adjusted mean (SD) & 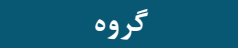 \\
\hline \multirow{2}{*}{$<\cdot / \cdot \cdot 1$} & \multirow{2}{*}{ IN/QT } & \multirow{2}{*}{$\cdot / K \mid(\cdot / / V, \cdot / F \Delta)$} & $\Gamma \Delta / \Delta \cdot(T / T r)$ & زايمان طبيعى \\
\hline & & & ( & زايمان فيزيولوزيك \\
\hline
\end{tabular}

جدول ه. مقايسُٔ هماتوكريت 9 ساعت يس از زايمان در دو كروه با كنترل عوامل مداخلهَّ

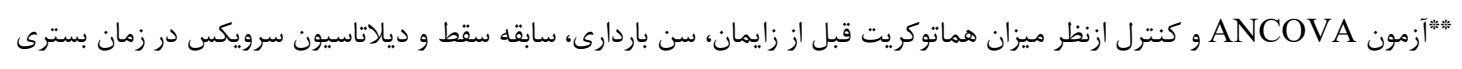




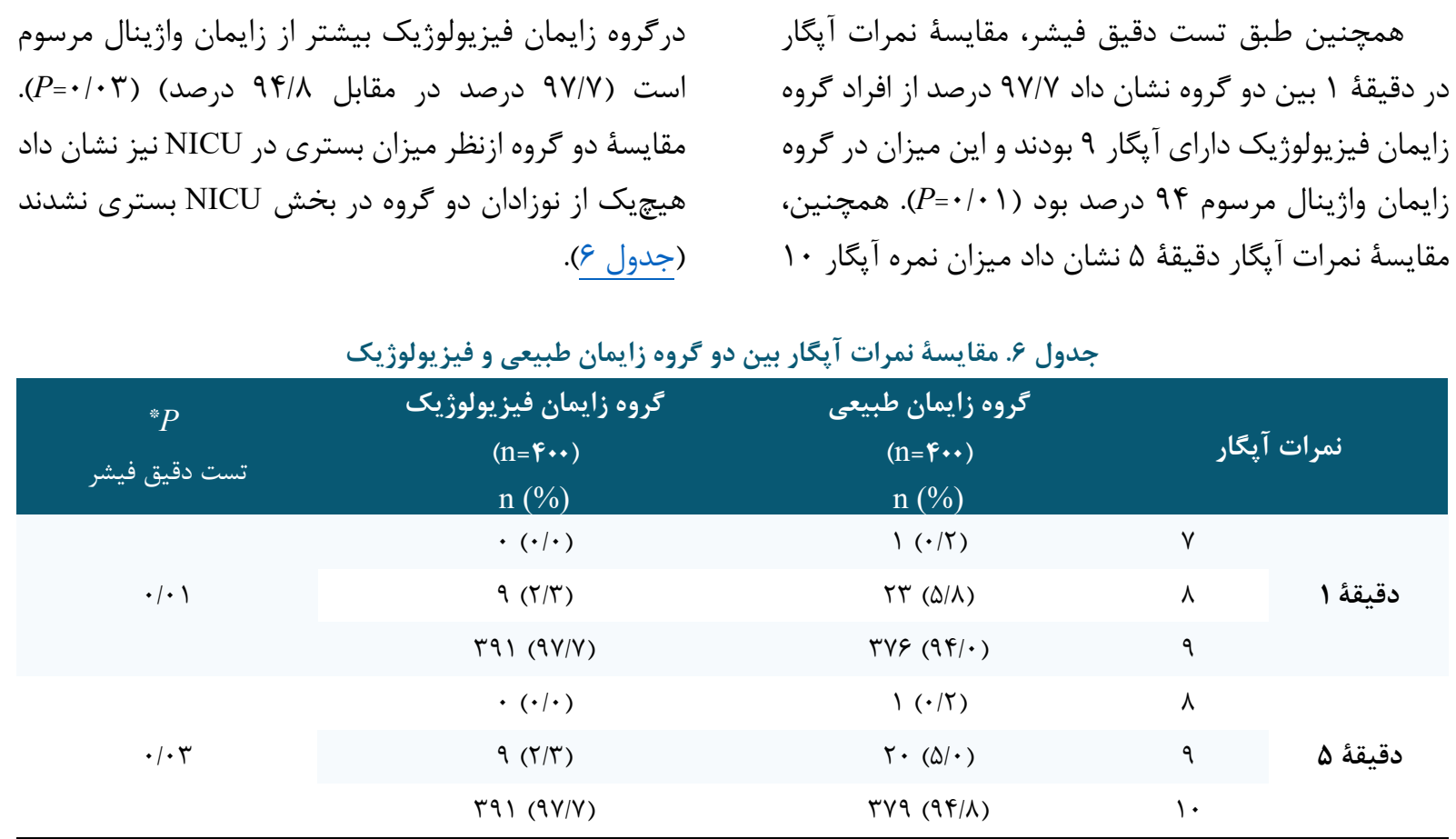

\section{بحث}

بدون إيىزياتومى در كروه زايمان فيزيولوزيك بيشتر از كروه

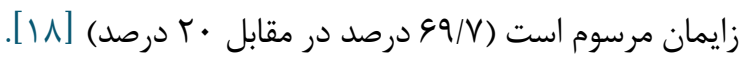

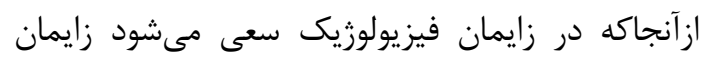

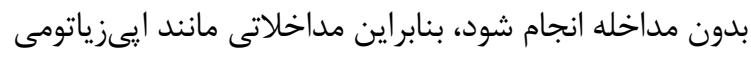

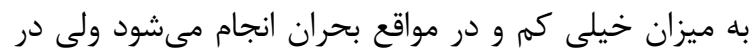
زايمان طبيعى استفاده از ايىزياتومى رايج است. ازآنجاكه دئه

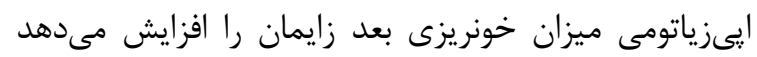

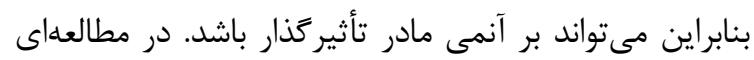

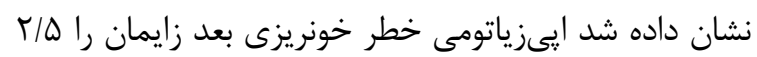

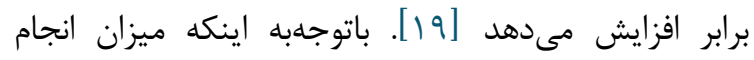

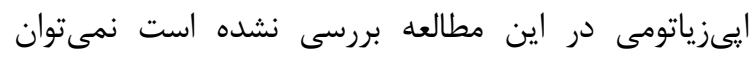

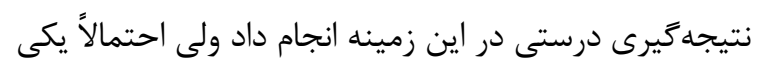

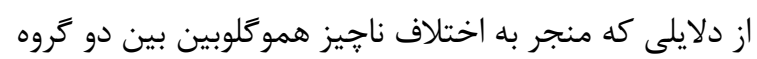

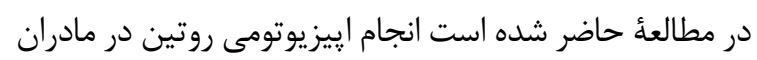

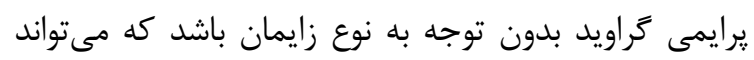

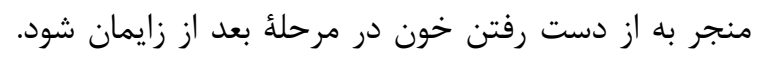

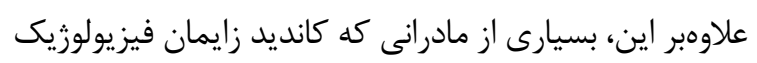

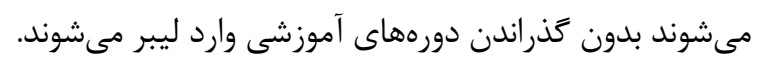

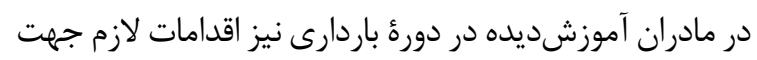

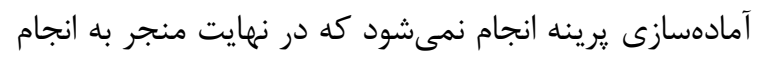

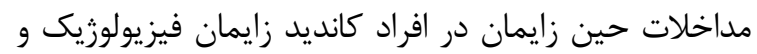

مطالعُ حاضر با هدف مقايسٔ ميزان هموكلوبين و

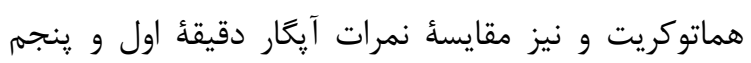

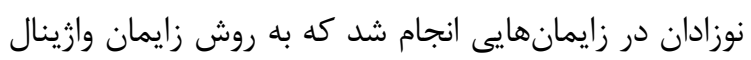
مرسوم يا زايمان فيزيولوزيك در بيمارستان فاطميه همدان روى مىدادند. يافتههاى مطالعأ حاضر نشان دان داد ميزان فئان

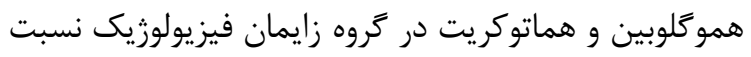

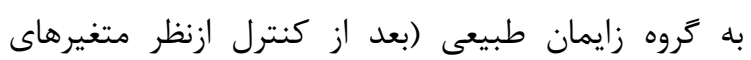

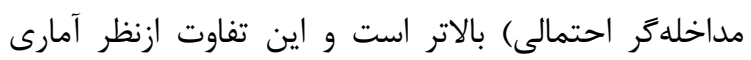

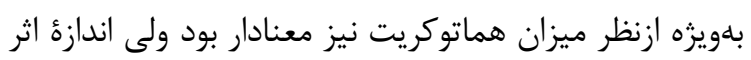

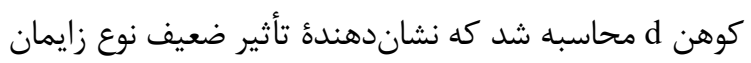

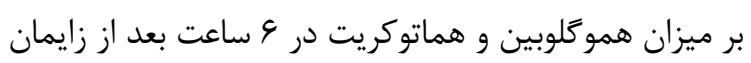

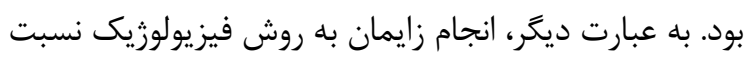

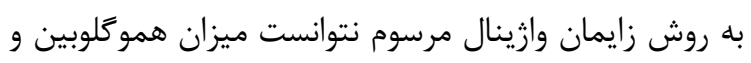

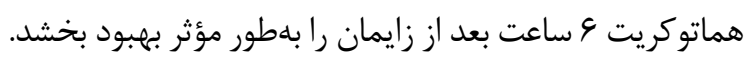

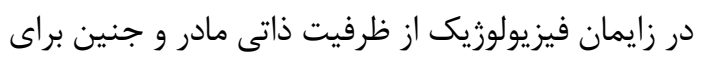

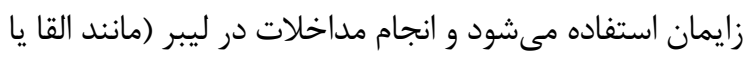
تقويت ليبر، استفاده از بيدردى، ناشتا نكَه داشتن مادر و و ....)

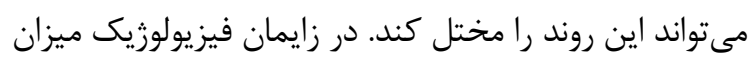

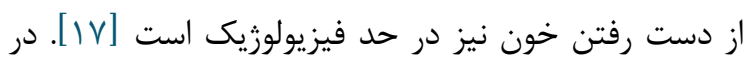
مطالعه Kazemi و همكاران كه به بررسى ارتباط طول مر دراحل

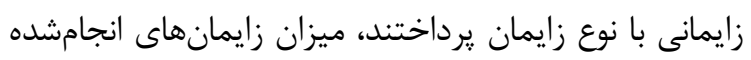


مادران استفاده مىشود و جون مرحلة سوم در مادرانى كه به

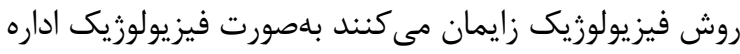
نمىشود، مى توان انتظار داشت ميزان خون از دست رفتئ رئه نيز در دو گروه مشابه باشد و همين امر باعث اختلاف ناجيز

همو كلوبين و هماتوكريت مادران در دو گروه شده باشد. همجنين در يزوهش حاضر، مقايسٔ نمرات آيخار در دقيقة ا و ه بين دو گروه نشان داد وضعيت نوزادان در زايمانهايى دراضي كه به روش فيزيولوزيك انجام مىشوند بهتر از روش زايمان مرسوم است. نتايج مطالعه حاضر همسو با نتايج مطالعئ Jahadi اين مطالعات نشان داد آيخار دقيقه إ و ه در كروه زايمان

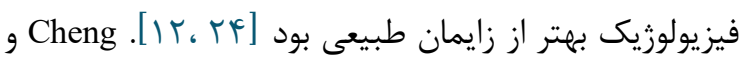

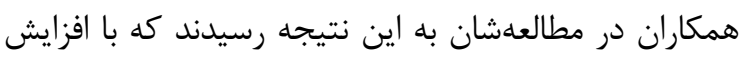

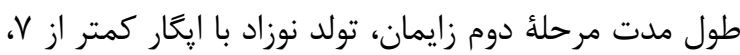
نياز به احياى نوزاد و ميزان ph بايين خون بندناف در كروه

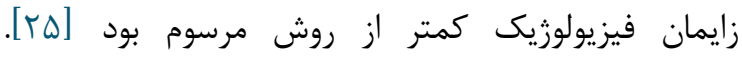
Moghimi-Hanjani دادند استفاده از رفلكسولوزى بهعنوان يكى از مداخلات كارامد در زايمان فيزيولوزيك سبب بهبود و افزايش نمره آيخار شده آنهاتي

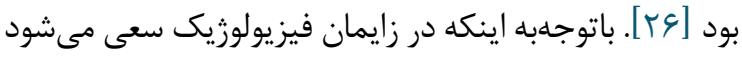
كمترين مداخلات بر روى مادر انجام شود و از طرف ديخر بهعلت كاهش مداخلات غيرضرورى تعادل در سيستم ردائم هورمونى مادر برقرار است و سطح آدرنالين در كمترين ميزان فئن قرار دارد، در نتيجه ترس و اضطراب كاهش يافته و ييشرفت ليبر بهخوبى انجام مىشود و مىتوان انتظار داشت بيامدهاى

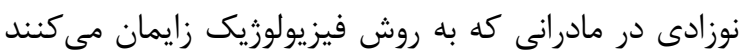
بهتر از مادرانى باشد كه به روش مرسوم فرزند خود را متولد في دئ مى كنند.

مطالعُ Weinberger و همكاران و نيز Rahimikian و

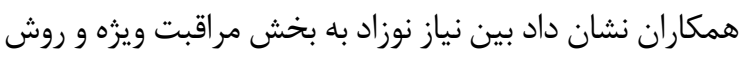
زايمان (طبيعى و فيزيولوزيك) ارتباط معنادارى وجود داشت ندان ندان

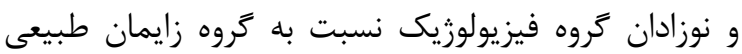

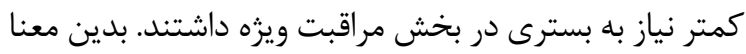

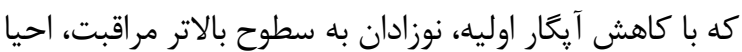

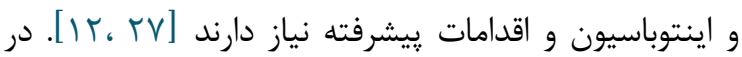
مطالعهُ Jahadi و همكاران، اختلاف معنادارى ازنظر نمره آيكار

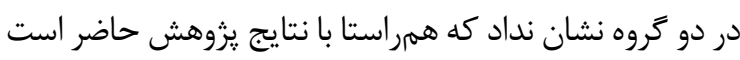

زايمان طبيعى مىشود. براى تمامى مادران بسترىشده در

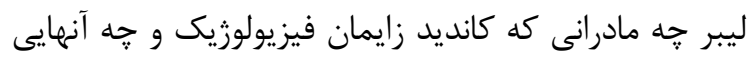
كه كانديد زايمان به روش مرسوم هستند، اقدامات كمكى

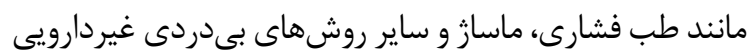

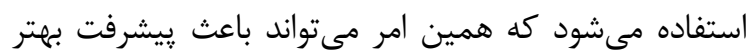
ليبر و كاهش مداخلات غيرضرورى در هر دو كروه شود و

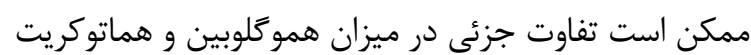
بين دو تروه ناشى از اين مسئله باشد.

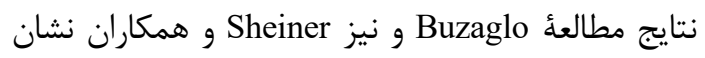
داد القا با اكسىتوسين مىتواند منجر به خونريزى بعد زايمان و همجنين افت هموكلوبين و هماتوكريت بعد زايمان شود. علت اين خونريزى به دنبال القا با اكسىتوسين، افزايش خطر

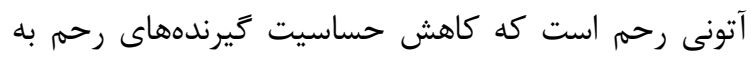

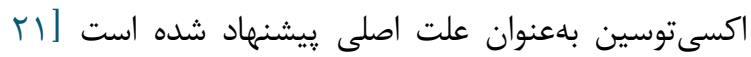

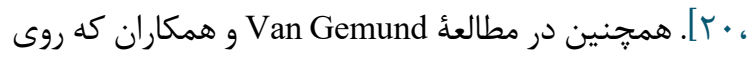
دو گروه ليبر خود به خود و ليبر القاشده جهت بران مدرسى ميزان مداخلات در طول ليبر انجام شد، ميزان تسكينبخشى، زايمان همراه با إيىزياتومى، فشار بر فوندوس جهت خرات خروج سريعتر سر در مرحلئ دوم زايمان، استفاده از اكسىتوسين و مترني

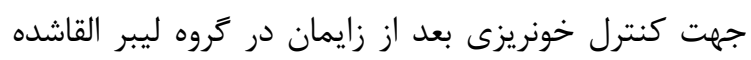

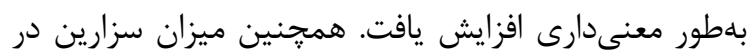
كروه ليبر القاشده به دليل عدم ييشرفت ليبر و افت ضربان

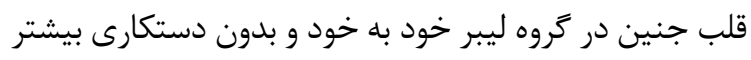

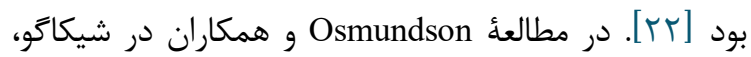
ييامدهاى مادرى و نوزادى، ميزان إيىزياتومى و خونريزى بعد از زايمان در دو گروه القاى الكتيو زايمان و و زايمان

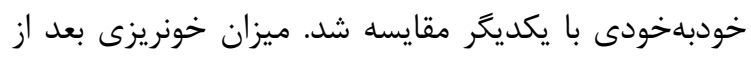

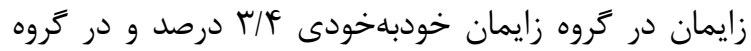

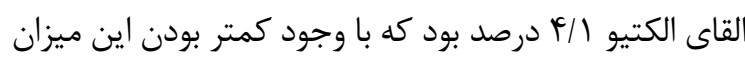

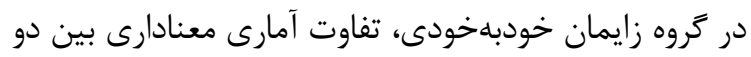

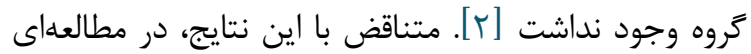

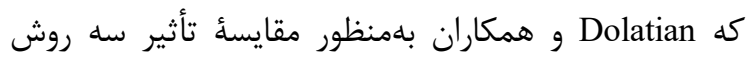
استفاده از سنتوسينون، سنتومترين و ادارئ فيزيولوزيك مر حلئ سوم زايمان انجام دادند به اين نتيجه رسيدند كه در كروه ادارئ فيزيولوزيك مرحله سوم، ميزان خونريزى بيشتر و ميزان

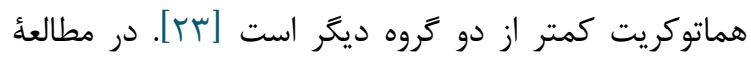

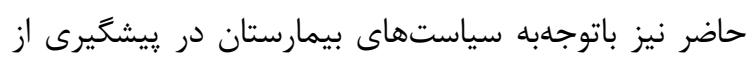

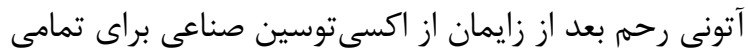




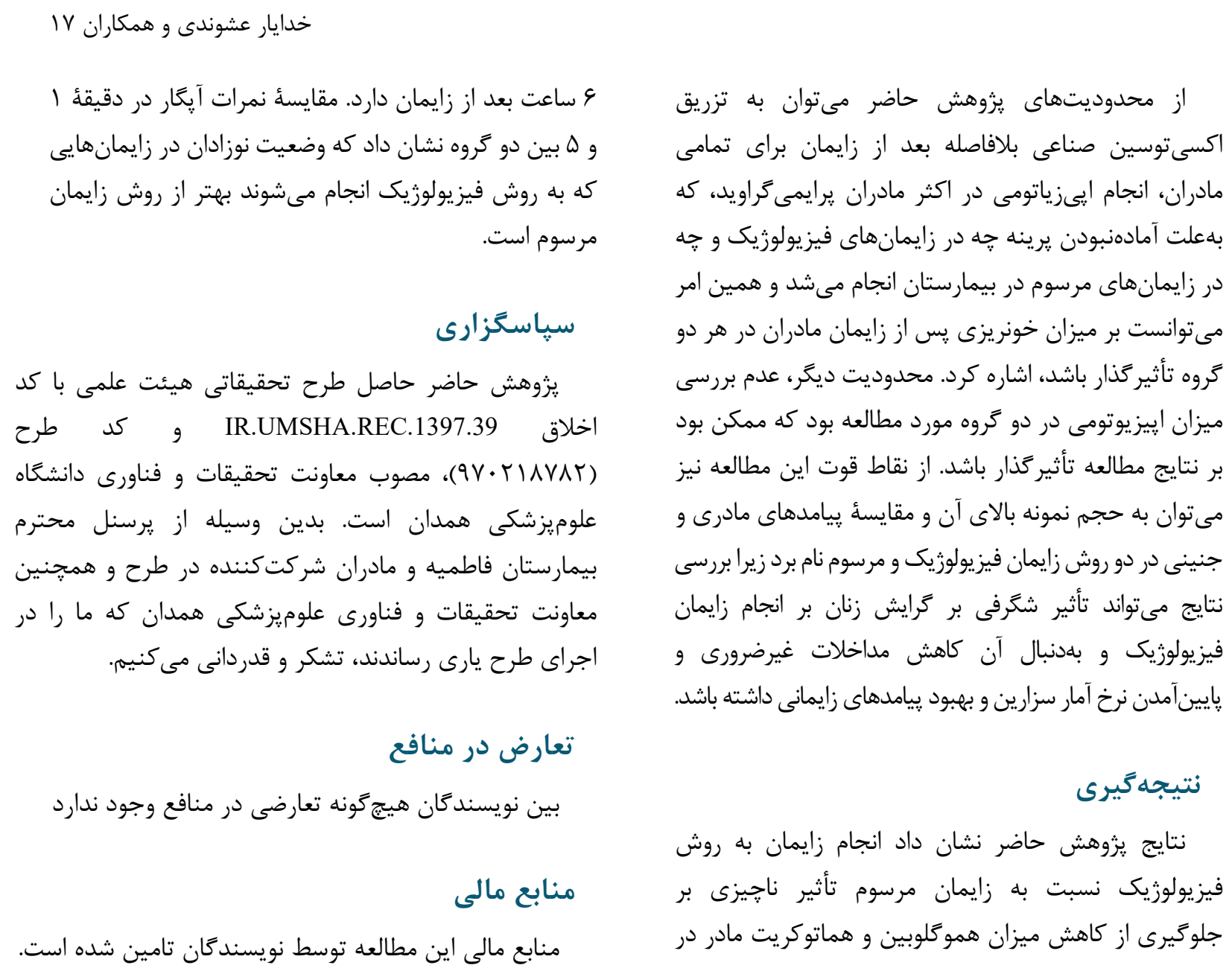$$
\text { نتيجه كَيرى }
$$

نتايج يزوهش حاضر نشان داد انجام زايمان به روش

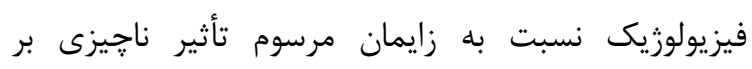

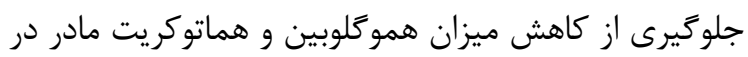

\section{References}

1. Abbaspoor Z, Vaziri L, Emam J. Sensitivity and specificity collector bag for the measurement of post-partum hemorrhage. $\mathrm{J}$ Guilan Univ Med Sci. 2012; 21(83):58-64.

2. Osmundson SS, Ou-Yang RJ, Grobman WA. Elective induction compared with expectant management in nulliparous women with a favorable cervix. Obst Gynecol. 2010; 116(3):601-5. [DOI:10.1097/AOG.0b013e3181eb6e9b] [PMID]

3. Miller S, Tudor C, Thorsten V, Quzong K, Dekyi T, Hartwell T, et al. Randomized double masked trial of Zhi Byed 11, a Tibetan traditional medicine, versus misoprostol to prevent postpartum hemorrhage in Lhasa, Tibet. J Midwifery Women Health. 2009; 54(2):133-41. [DOI:10.1016/j.jmwh.2008.09.010] [PMID] [PMCID]

4. Samimi M, Moravveji SA, Heidari-Shirazi F. The effect of tranexamic acid on pregnancy outcome and vaginal post- parturition hemodynamics. Feyz J Kashan Univ Med Sci. 2013; 17(2):114-22.

5. Nama V, Chandraharan E. Massive obstetric haemorrhage. In E. Chandraharan, \& S. Arulkumaran editors. Obstetric and Intrapartum Emergencies: A Practical Guide to Management. Cambridge: Cambridge University Press; 2012.

6. Shakur H, Elbourne D, Gülmezoglu M, Alfirevic Z, Ronsmans C, Allen E, et al. The WOMAN Trial (World Maternal Antifibrinolytic Trial): tranexamic acid for the treatment of postpartum haemorrhage: an international randomised, double blind placebo controlled trial. Trials. 2010; 11(1):40. [DOI:10.1186/1745-6215-11-40] [PMID] [ $\underline{\text { PMCID] }}$

7. Nasohi J, Falakaflaki B. The Magnitude of Hemoglobin-Drop in Obstetrics and Gynecologic Operations (Is Routine $\mathrm{Hb}$ Check Necessary?). Sci J Hamadan Univ Med Sci. 2004; 10(4):43-6.

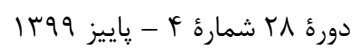




$$
\text { \1 يارامترهاى خونى مادران و نمرات آيخار نوزادان }
$$

8. Samimi M, Abedzadeh Kalahroudi M, Imani A. Comparison of the Effect of Rectal Misoprostol and IM Syntometrin in the Prevention of Post Partum Hemorrhage. Sci J Hamadan Univ Med Sci. 2011; 18(2):3844.

9. Shirazi M. The mangement of post partum haemorrhage. Iran J Obs Gynecol Infert. 2010; 5(3):14-29.

10. Cunningham FG, Bloom SL, Hauth JC, Rouse DJ, Spong CY, et al. Conduct of normal labor and delivery. New York: McGraw-Hill; 2010.

11. Gibbs RS, Karlyn BY, Haney AF, Nygaard I. Danforth's obstetrics and gynecology. Philadelphia: Wolters Kluwer Health Adis (ESP); 2012.

12. Rahimikian F, Talebi F, Golian Tehrani S, Mehran A. Comparison of the effect of physiological birth and routine normal delivery on some of maternal and fetus outcomes. J Ardabil Univ Med Sci. 2013; 13(4):398-405.

13. Sagiry M, Tabrizy N, Pezeshky Z. Comparison severity pain with use entonox and outcome neonatal in primary gravity. J Ardabil Univ Med Sci. 2008; 1(8):62-7.

14. Ghalandari S, Kariman N, Sheikhan Z, Shahrahmani H, Asadi N. Systematic review on variety of effective treatment methods for postpartum hemorrhage in Iran and world. Iran J Obst Gynec Infert. 2016; 19(15):1638.

15. Jafari E, Mohebbi P, Rastegari L, Mazloomzadeh S. The comparison of physiologic and routine method of delivery in mother's satisfaction level in Ayatollah Mosavai Hospital, Zanjan, Iran, 2012. Iran J Obst Gynec Infert. 2013; 16(73):9-18.

16. Zibad HA, Moghadam KB, Moghadam MB, Binabaj NB, Rafat E. The Correlation between Type of Delivery and Umbilical Cord Blood Hemoglobin and Hematocrit in Full-Term Neonates. J Isfahan Med School. 2012; 29(163):1298-305.

17. Supporting Healthy and Normal Physiologic Childbirth: A Consensus Statement by ACNM, MANA, and NACPM. J Perinat Educ. $\quad 2013 ; \quad 22(1): 14-8$. [DOI:10.1891/1058-1243.22.1.14] [PMID] [PMCID]
18. Kazemi S, Ghojazadeh M. Relationship between length of delivery stages and mode of delivery for nulliparus women in labor in two groups of physiological and tradithional delivery. Iran J Obst Gync infert. 2014; 17(117):17-25.

19. Biguzzi E, Franchi F, Ambrogi F, Ibrahim B, Bucciarelli P, Acaia B, et al. Risk factors for postpartum hemorrhage in a cohort of 6011 Italian women. Thromb Res. 2012; 129(4):e1-e7.

[DOI:10.1016/j.thromres.2011.09.010] [PMID]

20. Buzaglo N, Harlev A, Sergienko R, Sheiner E. Risk factors for early postpartum hemorrhage (PPH) in the first vaginal delivery, and obstetrical outcomes in subsequent pregnancy. J Matern-Fet Neonat Med. 2015; 28(8):932-7. [DOI:10.3109/14767058.2014.937698] [PMID]

21. Sheiner E, Sarid L, Levy A, Seidman DS, Hallak M. Obstetric risk factors and outcome of pregnancies complicated with early postpartum hemorrhage: a population-based study. J Matern-Fet Neonat Med. 2005; 18(3):149-54.

[DOI:10.1080/14767050500170088] [PMID]

22. Van Gemund N, Hardeman A, Scherjon S, Kanhai $\mathrm{H}$. Intervention rates after elective induction of labor compared to labor with a spontaneous onset. Gynecol Obs Invest. 2003; 56(3):133-8. [DOI:10.1159/000073771] [PMID]

23. Dolatian M, Shademani N, Sharafi SA, Valaei N. Efficacy of Syntometrine, Syntocinon and the Physiologic Approach in the Management of the Third Stage of Labor. Pejouhesh dar Pezeshki (Res Med). 2003; 27(3):191-6.

24. Jahdi F, Shanazari Avag M, Kashanian M, Ashgehi Farahani M, Hagani H. The effect of physiological birth in outcomes of delivery [dissertation]. Tehran university. 2009.

25. Cheng YW, Delaney SS, Hopkins LM, Caughey AB. The association between the length of first stage of labor, mode of delivery, and perinatal outcomes in women undergoing induction of labor. America $\mathrm{J}$ Obst Gynec. 2009; 201(5):477. [DOI:10.1016/j.ajog.2009.05.024] [PMID]

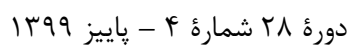

$$
\text { مجله مراقبت يرستارى و مامايى ابنسينا }
$$


خدايار عشوندى و همكاران 19

26. Moghimi-Hanjani S, Mehdizadeh-Tourzani Z , Shoghi M.The Effect of Foot Reflexology on Anxiety, Pain, and Outcomes of the Labor in Primigravida Women. Acta Med Iran. 2015; 53(8):50711.

27. Weinberger B, Anwar M, Hegyi T, Hiatt M, Koons A, Paneth N. Antecedents and neonatal consequences of low Apgar scores in preterm newborns: a population study. Arch Pediat Adol Med. 2000; 154(3):294300. [DOI:10.1001/archpedi.154.3.294] [PMID] 